\title{
Determinants and constraints to household-level animal source food consumption in rural communities of Ethiopia
}

\author{
Alemneh Kabeta Daba ${ }^{1,2} *$ (D), Mary Murimi ${ }^{3}$, Kebede Abegaz ${ }^{1}$ and Dejene Hailu ${ }^{4}$ \\ ${ }^{1}$ School of Nutrition, Food Science and Technology, College of Agriculture, Hawassa University, Hawassa, Ethiopia \\ ${ }^{2}$ School of Nursing, College of Medicine and Health Sciences, Hawassa University, Hawassa, Ethiopia \\ ${ }^{3}$ Department of Nutritional Sciences, College of Human Sciences, Texas Tech University, Lubbock, TX, USA \\ ${ }^{4}$ School of Public Health, College of Medicine and Health Sciences, Hawassa University, Hawassa, Ethiopia
}

(Received 25 March 2021 - Final revision received 6 July 2021 - Accepted 16 July 2021)

Journal of Nutritional Science (2021), vol. 10, e58, page 1 of 10

doi:10.1017/jns.2021.52

Abstract

Animal source foods (ASF) contain quality nutrients important for growth, development, immunity and behavioural outcomes. Plant-based foods also provide the nutrients, but with lower bioavailability than ASF. Evidence on household-level ASF consumption frequency, constraints and determinants are limited for Ethiopia. Therefore, the present study aimed to assess the consumption frequency of ASF and to identify determinants and constraints among rural households in Ethiopia. A cross-sectional study was conducted in 422 households. The consumption frequency of ASF was assessed using a food frequency screener over 30 days. Twelve statements with Likert scale responses were used to identify constraints to ASF consumption. Ordinal logistic regression was used to identify determinants of ASF consumption. About a quarter $(26 \%)$ of the households consumed milk one to two times per week. One out of five households consumed eggs one to two times per week $(20 \%)$ or one to two times per month $(19 \%)$. Poultry and meat were never consumed by 92 and $60 \%$ of the households, respectively. Unavailability, unaffordability, consumption tradition and income generation priority were constraints identified. Food insecurity, livestock ownership, income, family size and women's education were associated $(P<0 \cdot 05)$ with selected ASF consumption. Rural households in Ethiopia did not consume ASF on regular basis. Poor socio-demographic and economic conditions as determined by food insecurity, property ownership, income, educational achievement, family size and ASF unavailability and unaffordability contributed to the lower consumption frequency of ASF by households in rural Ethiopia. Nutrition policies and programmes should focus on nutrition-sensitive agricultural extension, livelihood improvement and women empowerment interventions integrated with nutrition education to improve ASF consumption in rural settings.

Key words: Animal source foods: Consumption frequency: Constraints and determinants: Households in Ethiopia

\section{Introduction}

Malnutrition is a significant public health concern. Globally, out of 676 million children underfive ${ }^{(1)}, 155$ million are stunted and 52 million are wasted ${ }^{(2,3)}$. Worldwide, almost three million children die before the age of 5 years and 45 $\%$ of those deaths are attributed to malnutrition ${ }^{(4)}$. Africa is home to about fifty-nine million stunted and fourteen million wasted children in the world. Regionally, countries located in East Africa share $4 \cdot 1 \%$ of wasting and $24 \%$ of stunting ${ }^{(3)}$.
Undernutrition can be manifested as either growth failure or micronutrient deficiency, and a multitude of factors contribute to undernutrition ${ }^{(5)}$. For example, low animal source food (ASF) consumption has been reported to increase the risks of being undernourished $^{(6-8)}$. ASF are excellent sources of quality macroand micro-nutrients ${ }^{(9)}$ including all of the essential amino acids $^{(10)}$, zinc, iron, calcium, selenium, vitamin $\mathrm{A}$, vitamin $\mathrm{B}_{12}^{(11)}$ and vitamin $\mathrm{D}^{(12)}$. Having access to such foods is vital for bone

Abbreviations: AOR: adjusted odds ratio; ASF: animal source foods; BMI, body mass index; ETB: Ethiopian Birr; ha, hectare; IQR, Inter-quartile Range; SD, Standard Deviation; USA, United States of America; USAID, United States Agency for International Development; USD, United States' Dollar

* Corresponding author: Alemneh Kabeta Daba, email: alemneh33@gmail.com

(C) The Author(s), 2021. Published by Cambridge University Press on behalf of The Nutrition Society. This is an Open Access article, distributed under the terms of the Creative Commons Attribution licence (http://creativecommons.org/licenses/by/4.0/), which permits unrestricted re-use, distribution, and reproduction in any medium, provided the original work is properly cited. 
health, growth, healthy blood cell production, immunity, neurological function and behavioural outcomes ${ }^{(13-15)}$. Moreover, the addition of small quantities of ASF in a diet can improve the nutritional performance of plant-based diets and consumers' nutritional status $^{(15-17)}$. However, there are still many communities throughout the world that have poor or minimal access to $\mathrm{ASF}^{(18)}$.

Ethiopia has a high burden of malnutrition. According to the 2016 Ethiopian Demographic and Health Survey, within half a decade small decrements in stunting (44-38\%), wasting (12-10 $\%)$ and underweight (29-24\%) for children underfive were reported. In addition, more than half (56\%) of children underfive suffer from iron deficiency anaemia ${ }^{(19)}$. Ethiopia is committed to ending hunger and dramatically reducing stunting by $2030^{(20)}$ and emphasised the need for a moderate increase in ASF consumption ${ }^{(21)}$. Ethiopians consume on average onetenths as much meat as people in developed countries. Dietary diversity and other food consumption pattern assessments also reported that a limited proportion of diets in Ethiopia contain ASF. For example, according to a survey on household-level dietary diversity, diets in more than $90 \%$ of households were cereal-dominated with little inclusion of $\mathrm{ASF}^{(22)}$. Evidence from the Ethiopian National Food Consumption Survey ${ }^{(23)}$ and small area assessments reported that only a small proportion $(11-16 \%)^{(24-27)}$ of children met minimum dietary diversity recommendations ${ }^{(28)}$, and investigations documented ASF as the most limiting food group ${ }^{(29,30)}$.

Women and children are more vulnerable to malnutrition as compared to the general population and it is estimated that almost $30 \%$ of Ethiopian women of reproductive age had a body mass index (BMI) less than $18.5 \mathrm{~kg} / \mathrm{m}^{2(31)}$. A study ${ }^{(32)}$ in Ethiopia with the majority $(71 \%)$ of female participants also estimated that the intakes of nutrients available from ASF were below the recommended levels for protein (11\%), calcium (90\%) and vitamin A (100\%). Furthermore, almost a quarter $(23 \%)$ of women in the country had iron deficiency anaemia ${ }^{(19)}$ for which ASF have been found to be beneficial ${ }^{(33)}$. According to a study ${ }^{(34)}$ from northern Ethiopia, the proportion of lactating women who ate ASF was also low, with $17 \%$ consuming meat and fish, $18 \%$ eggs and $12 \%$ dairy products.

While ASF may protect against undernutrition, research on dietary patterns in Ethiopia has not addressed household-level ASF consumption patterns ${ }^{(22,25-27,29,30)}$. Furthermore, those published studies have not investigated constraints to and determinants of ASF consumption in the country. Hence, the purpose of the present study was to determine householdor family-level dietary behaviours related to the consumption of ASF and to identify facilitators, constraints to and determinants of ASF consumption. The findings of the present study can be a base to strategize and realise far-reaching food-based nutrition interventions and to reduce the magnitude of undernutrition among families in Ethiopia ${ }^{(35,36)}$.

\section{Materials and methods}

\section{Study area and design}

This cross-sectional study was conducted in rural kebeles (the lowest unit in Ethiopia's administrative structure) from the
Milkshed region of Hawassa, districts of Oromia and Sidama regional states. The milkshed includes Arsi Negelle (Oromia), Dale, Wondo Genet and other districts (Sidama) ${ }^{(37)}$.

\section{Sample size and sampling}

Sample size was calculated using a single population proportion formula ${ }^{(38)}$ considering $50 \%$ proportion (no findings on household-level ASF consumption frequency to base the estimate on), a $95 \%$ confidence level, 0.05 of $\alpha$ and $10 \%$ non-response rate. Data were collected from 422 households selected using a simple random sampling technique. Four kebeles were randomly selected from each district (twelve kebeles in total). An equal proportion allocation was applied to draw sample size from each of the selected kebeles. All the respondents were women who were responsible for food preparation for the family.

\section{Data collection}

Data were collected by individual interviews using a pre-tested questionnaire. The pre-test was done in districts from Oromia and Sidama regional states, but other than districts where the actual data were collected. The tool was constituted of four parts: (1) socio-demographic and economic characteristics, (2) household food-insecurity access scale ${ }^{(39)}$, (3) selected ASF consumption frequency screener and (4) facilitators and constraints to the consumption of specific ASF questionnaire in Likert scales.

The ASF consumption frequency screener for household(family-) level selected ASF consumption during the 30 days had closed-ended response options. These were 'greater than once per day', 'once per day', 'three to six times per week', 'one to two times per week', 'one to two times per fortnight', 'one to two times per month' and 'never consumed in the last month' for consumption frequencies of meat, poultry, fish, eggs, milk and milk products.

Data on facilitators and constraints to the consumption of ASF were collected using predefined statements with five-level Likert scale response options. The statements focused on quality, availability, affordability, price of ASF as compared to plant-based food, effort involved to prepare food products from the specific ASF, ASF storage facilities, health beliefs about specific ASF, medical concern related to the consumption of ASF, ASF consumption tradition during childhood, religious restrictions on the consumption of ASF, fasting restrictions to ASF consumption and income generation priority from livestock rearing. The twelve predefined statements included items such as 'The quality of meat/fish/eggs/milk/ milk products is important for me', 'I am able to afford meat/fish/eggs/milk/milk products', 'Eating plant-based foods is more affordable for us than eating meat/fish/eggs/ milk/milk products' and others. All statements were provided with response options of-'strongly agree/ slightly agree/ neither agree nor disagree/ slightly disagree/ strongly disagree.'

The data collectors attended 3 days training on the basics of data collection methods, research ethics and the purpose of the present study. The principal investigator supervised data collection and reviewed the questionnaires for completeness. 


\section{Data analysis}

Data were coded and entered into SPSS version 20 for Windows and cleaned. Frequencies, proportions, mean or median scores and standard deviations (SD) or inter-quartile ranges (IQR) were computed. After checking for the existence of multicollinearity, predictors of specific ASF consumption frequency were identified with the application of cumulative odds ordinal logistic regression with proportional odds model at significance set at $P<0 \cdot 05$. The regression analysis was not done for fish because it was consumed by a small proportion of households in 30 days before the survey.

\section{Ethical consideration}

The present study was conducted according to the guidelines laid down in the Declaration of Helsinki, and all procedures involving human subjects were approved by the Institutional Review Board of Hawassa University (Ref. No.: IRB/027/ 10). Verbal informed consent was obtained from all subjects before data collection. Verbal consent was witnessed and formally recorded.

\section{Results}

\section{Socio-demographic and economic characteristics}

Almost all of the women were married (96\%) and $81 \%$ were homemakers. Regarding education, some of the respondents (34\%) had completed from grades one to five, while $43 \%$ had completed from grades six to twelve. Respondents' mean (SD) age was $25 \cdot 55$ (4.96) years. The majority of the participants identified themselves as Sidama $(61 \%)$ by ethnicity and protestant $(67 \%)$ (Table 1$)$.

More than half $(57 \%)$ of the households had four to six family members, and almost all (94\%) were male-headed. The median (IQR) annual household income was 6650 (3000, 15 000) Ethiopian Birr (ETB) [1USD $\approx$ Birr 30 50]. This monetary income is minor in the rural family settings, where their major living expenditures are derived in-kind from their own agricultural produce, and their lifestyle is associated with low-cost family labour and with natural utilities like fuel/energy, water and housing materials. The majority $(80 \%)$ of the households earned less than 15000 ETB or $\$ 491$ annually on top of farm goods and services that make their major living. Decisions on household needs were made by the women for $58 \%$ of the households or by both husband and wife for $31 \%$ of the households. Almost all (95\%) households owned different amounts of agricultural land with $48 \%$ of the households owning less than 1 ha. Concerning domestic animal ownership, about $43 \%$ of households owned cows and $41 \%$ owned chickens. More than half $(54 \%)$ of the households were food insecure (Table 1).

\section{Consumption frequency of animal source foods}

Poultry products were not consumed in $92 \%$ of households during the month before the survey. Meat from sheep or lamb, goat, beef or cattle and other large animals was
Table 1. Socio-demographic and economic characteristics of households and respondents from Hawassa Milkshed, Ethiopia ( $N 422)$

\begin{tabular}{|c|c|c|}
\hline Variables & $N$ & $\%$ \\
\hline \multicolumn{3}{|l|}{ Respondents' characteristics } \\
\hline \multicolumn{3}{|l|}{ Educational status } \\
\hline Never attended school & 87 & $20 \cdot 6$ \\
\hline Grades $1-5$ & 144 & $34 \cdot 3$ \\
\hline Grades 6-12 & 179 & $42 \cdot 6$ \\
\hline College and above & 12 & $2 \cdot 8$ \\
\hline \multicolumn{3}{|l|}{ Marital status } \\
\hline Married & 407 & $96 \cdot 4$ \\
\hline Single & 15 & 3.5 \\
\hline \multicolumn{3}{|l|}{ Age (in completed years) } \\
\hline$\leq 18$ & 25 & 5.9 \\
\hline $19-30$ & 335 & 79.4 \\
\hline$\geq 31$ & 62 & $14 \cdot 6$ \\
\hline \multicolumn{3}{|l|}{ Ethnicity } \\
\hline Sidama & 257 & $60 \cdot 9$ \\
\hline Oromo & 132 & $31 \cdot 3$ \\
\hline Wolayta & 13 & $3 \cdot 1$ \\
\hline Others & 20 & $4 \cdot 7$ \\
\hline \multicolumn{3}{|l|}{ Religion } \\
\hline Protestant & 283 & $67 \cdot 0$ \\
\hline Muslim & 117 & $27 \cdot 7$ \\
\hline Orthodox & 14 & $3 \cdot 3$ \\
\hline Catholic & 8 & 1.9 \\
\hline \multicolumn{3}{|l|}{ Occupation } \\
\hline Homemaker & 343 & $81 \cdot 3$ \\
\hline Farmer & 31 & $7 \cdot 3$ \\
\hline Merchant & 30 & $7 \cdot 1$ \\
\hline Others & 14 & 3.7 \\
\hline \multicolumn{3}{|l|}{ Households' characteristics } \\
\hline \multicolumn{3}{|c|}{ Estimated annual income in ETB/US dollar (\$) } \\
\hline$\leq 5000 / \$ 163$ & 182 & $46 \cdot 4$ \\
\hline $5001-15000 / \$ 164-492$ & 131 & 33.8 \\
\hline $15001-30000 / \$ 492-983$ & 57 & $14 \cdot 7$ \\
\hline$\geq 30001 / \$ 984$ & 34 & $8 \cdot 8$ \\
\hline \multicolumn{3}{|l|}{ Head } \\
\hline Woman & 17 & $4 \cdot 0$ \\
\hline Man & 396 & 93.9 \\
\hline Grandparent/s & 9 & $2 \cdot 1$ \\
\hline \multicolumn{3}{|c|}{ Who decides on daily household needs? } \\
\hline Woman & 246 & $58 \cdot 3$ \\
\hline Man & 39 & 9.2 \\
\hline Both husband and wife & 130 & $30 \cdot 8$ \\
\hline Others & 7 & $1 \cdot 7$ \\
\hline \multicolumn{3}{|c|}{ Who decides how household income used? } \\
\hline Woman & 74 & $17 \cdot 5$ \\
\hline Man & 90 & $21 \cdot 3$ \\
\hline Both husband and wife & 251 & 59.5 \\
\hline Others & 7 & 1.7 \\
\hline \multicolumn{3}{|l|}{ Family size } \\
\hline$\leq 3$ & 73 & $17 \cdot 3$ \\
\hline $4-6$ & 240 & $56 \cdot 9$ \\
\hline$\geq 7$ & 109 & $25 \cdot 8$ \\
\hline \multicolumn{3}{|l|}{ Domestic animal ownership } \\
\hline Ox & 99 & $23 \cdot 4$ \\
\hline Cow & 181 & $42 \cdot 8$ \\
\hline Goat & 50 & $11 \cdot 7$ \\
\hline Sheep & 39 & $9 \cdot 2$ \\
\hline Chicken & 175 & $41 \cdot 4$ \\
\hline Agriculture land ownership ( & & \\
\hline No agriculture land & 21 & 5 \\
\hline$<1$ & 197 & $46 \cdot 7$ \\
\hline $1-2$ & 161 & 38.2 \\
\hline$>2$ & 43 & $10 \cdot 2$ \\
\hline Food insecurity & & \\
\hline Secure & 196 & $46 \cdot 4$ \\
\hline Insecure & 226 & $53 \cdot 6$ \\
\hline
\end{tabular}


Table 2. Consumption frequency of ASF by households from Hawassa Milkshed, Ethiopia ( $N$ 422)

\begin{tabular}{|c|c|c|c|}
\hline Animal source food & Consumption frequency & $N$ & $\%$ \\
\hline \multirow[t]{3}{*}{ Poultry } & More than once per day to one to two times per fortnight & 11 & $2 \cdot 6$ \\
\hline & One to two times per month & 24 & $5 \cdot 7$ \\
\hline & Never consumed & 387 & $91 \cdot 7$ \\
\hline \multirow[t]{4}{*}{ Meat (sheep/lamb, goat, beef/cattle and any other animals) } & More than once per day to one to two times per week & 42 & $10 \cdot 0$ \\
\hline & One to two times per fortnight & 17 & 4.0 \\
\hline & One to two times per month & 110 & $26 \cdot 1$ \\
\hline & Never consumed & 253 & $60 \cdot 0$ \\
\hline \multirow[t]{2}{*}{ Fish products } & More than once per day to one to two times per month & 11 & $2 \cdot 6$ \\
\hline & Never consumed & 411 & $97 \cdot 4$ \\
\hline \multirow[t]{6}{*}{ Eggs } & More than once or once per day & 12 & $2 \cdot 8$ \\
\hline & Three to six times per week & 32 & $7 \cdot 6$ \\
\hline & One to two times per week & 86 & $20 \cdot 4$ \\
\hline & One to two times per fortnight & 20 & $4 \cdot 7$ \\
\hline & One to two times per month & 81 & $19 \cdot 2$ \\
\hline & Never consumed & 191 & $45 \cdot 3$ \\
\hline \multirow[t]{6}{*}{ Milk } & More than once or once per day & 90 & $21 \cdot 3$ \\
\hline & Three to six times per week & 47 & $11 \cdot 1$ \\
\hline & One to two times per week & 108 & $25 \cdot 6$ \\
\hline & One to two times per fortnight & 22 & $5 \cdot 2$ \\
\hline & One to two times per month & 76 & $18 \cdot 0$ \\
\hline & Never consumed & 79 & $18 \cdot 7$ \\
\hline \multirow[t]{6}{*}{ Milk products (yogurt, cheese, whey, etc.) } & More than once or once per day & 18 & 4.3 \\
\hline & Three to six times per week & 20 & 4.7 \\
\hline & One to two times per week & 30 & $7 \cdot 1$ \\
\hline & One to two times per fortnight & 24 & $5 \cdot 7$ \\
\hline & One to two times per month & 66 & $15 \cdot 6$ \\
\hline & Never consumed & 264 & $62 \cdot 6$ \\
\hline
\end{tabular}

consumed one to two times per month by $26 \%$ of the households. Fish products were only consumed by $3 \%$ of the households.

Milk was consumed once per day by less than one-quarter of the households $(21 \%)$ and by a quarter $(26 \%)$ one to two times per week. Milk products like yogurt and cheese were consumed one to two times per month by $15 \%$ of the households. Eggs were consumed one to two times per week by $20 \%$ and one to two times per month by $19 \%$ of households (Table 2).

\section{Facilitators to the consumption of animal source foods}

Nearly all of the study participants $(97 \%)$ agreed with the statement 'The quality of meat is important for me', and $98 \%$ agreed that eating meat is good for their health. About $64 \%$ of the participants did not agree with the statement 'It takes a lot of effort to prepare and cook meat'; and $70 \%$ did not perceive lack of proper meat storage technologies as a barrier to meat consumption. The majority of the participants reported that they did not have religious prohibition on the consumption of meat (91\%), eggs $(91 \%)$ and dairy products (93\%). Nearly all of the respondents (92\% for meat, $94 \%$ for egg and $94 \%$ for dairy) disagreed with the statement 'I don't eat meat/egg/ dairy products when I am fasting.'

About two-thirds of the participants reported that they can afford eggs $(60 \%)$, and the majority reported that eggs are available $(78 \%)$ where they shop. Lack of proper egg storage facility did not prevent the majority of the study participants (76\%) from egg consumption.

The majority of participants $(76 \%)$ reported that milk and milk products were regular components of their diet while growing up as children. About $82 \%$ of respondents agreed that milk and milk products are available where they usually shop, and more than two-thirds $(70 \%)$ agreed that they could afford milk and milk products (Supplementary Table S1).

\section{Constraints to the consumption of animal source foods}

Most of the participants (70\%) agreed that it is difficult to get meat where they usually shop, while the majority of them $(80$ $\%$ indicated that they cannot afford meat (Supplementary Table S1). The majority reported that plant-based food products were more affordable than meat $(92 \%)$, eggs $(93 \%)$, dairy $(90 \%)$ and fish $(91 \%)$. About half $(50 \%$ for meat and $57 \%$ for fish) of the participants disagreed with the statement 'Meat or fish was a regular component of my diet while growing up.' Almost all of the respondents $(99 \%)$ indicated that fish was not available where they usually shop, while more than half of the participants $(58 \%)$ reported that they could not afford fish (Supplementary Tables S1 and S2).

\section{Determinants of household-level animal source food consumption frequency}

Household food insecurity was significantly associated with consumption frequencies of all ASF types. Food-insecure households were less likely to consume poultry (adjusted odds ratio (AOR) $0.35, P$ 0.035), meat (AOR $0.25 P<$ $0 \cdot 001$ ), eggs (AOR 0.44, $P<0.001$ ), milk (AOR 0.66, $P$ 0.035 ) and milk products (AOR 0.52, P 0.005 ) than foodsecure households (Tables 3 and 4 ).

Family size was a factor in poultry and meat consumption patterns. Households with four to six (AOR 0.34, P 0.029) 
Table 3. Ordinal logistic regression analysis on predictors of poultry, meat and egg consumption frequencies by households in Hawassa Milkshed, Ethiopia $(N 422)$

\begin{tabular}{|c|c|c|c|c|c|c|}
\hline \multirow[b]{2}{*}{ Characteristics } & \multicolumn{2}{|c|}{ Poultry } & \multicolumn{2}{|c|}{ Meat } & \multicolumn{2}{|c|}{ Eggs } \\
\hline & AOR $(95 \% \mathrm{Cl})$ & $P$ & AOR $(95 \% \mathrm{Cl})$ & $P$ & AOR $(95 \% \mathrm{Cl})$ & $P$ \\
\hline \multicolumn{7}{|l|}{ Food Insecurity } \\
\hline Insecure & $0.35(0.13,0.93)$ & 0.035 & $0.25(0.16,0.40)$ & 0.000 & $0.44(0.29,0.66)$ & 0.000 \\
\hline Secure & 1 & & 1 & & 1 & \\
\hline \multicolumn{7}{|l|}{ Cash crops production } \\
\hline No & $0.40(0.11,1.46)$ & 0.168 & $0.98(0.46,2.09)$ & 0.954 & $0.92(0.46,1.86)$ & 0.822 \\
\hline Yes & 1 & & 1 & & 1 & \\
\hline \multicolumn{7}{|l|}{ Chicken ownership } \\
\hline No & $0.70(0.28,1.71)$ & 0.43 & $0.90(0.57,1.43)$ & 0.658 & $0.33(0.22,0.50)$ & 0.000 \\
\hline Yes & 1 & & 1 & & 1 & \\
\hline \multicolumn{7}{|l|}{ Donkey ownership } \\
\hline No & $0.25(0.08,0.78)$ & 0.017 & $0.38(0.18,0.77)$ & 0.008 & $0.55(0.29,1.03)$ & 0.06 \\
\hline Yes & 1 & & 1 & & 1 & \\
\hline \multicolumn{7}{|l|}{ Sheep ownership } \\
\hline No & $2.80(0.62,13.53)$ & 0.176 & $0.97(0.48,1.96)$ & 0.929 & $0.97(0.51,1.88)$ & 0.938 \\
\hline Yes & 1 & & 1 & & 1 & \\
\hline \multicolumn{7}{|l|}{ Goat ownership } \\
\hline No & $1.24(0.37,4.18)$ & 0.726 & $1.58(0.77,3.27)$ & 0.216 & $0.86(0.47,1.59)$ & 0.636 \\
\hline Yes & 1 & & 1 & & 1 & \\
\hline \multicolumn{7}{|l|}{ Cow ownership } \\
\hline No & $1.36(0.51,3.63)$ & 0.544 & $1.24(0.76,2.02)$ & 0.389 & $0.99(0.63,1.53)$ & 0.947 \\
\hline Yes & 1 & & 1 & & 1 & \\
\hline \multicolumn{7}{|l|}{ Ox ownership } \\
\hline No & $0.61(0.23,1 \cdot 64)$ & 0.324 & $1.56(0.88,2.77)$ & 0.132 & $0.86(0.52,1.41)$ & 0.541 \\
\hline Yes & 1 & & 1 & & 1 & \\
\hline \multicolumn{7}{|c|}{ Women's educational status } \\
\hline No education & $0.1(0.01,1.06)$ & 0.056 & $0.51(0.14,1.88)$ & 0.311 & $0.20(0.06,0.71)$ & 0.012 \\
\hline Grades 1-5 & $0.22(0.03,1.70)$ & 0.148 & $0.94(0.27,3.22)$ & 0.918 & $0.50(0.15,1.63)$ & 0.248 \\
\hline Grades 6-10 & $0.15(0.02,1.12)$ & 0.064 & $0.79(0.23,2.70)$ & 0.707 & $0.68(0.21,2.19)$ & 0.517 \\
\hline Higher education & 1 & & 1 & & 1 & \\
\hline \multicolumn{7}{|c|}{ Agriculture land ownership and size (ha) } \\
\hline No land & $4.29(0.23,80.12)$ & 0.33 & $1.67(0.44,6.28)$ & 0.45 & $1.66(0.48,5.74)$ & 0.427 \\
\hline$<1$ & $1.75(0.33,9.33)$ & 0.511 & $0.49(0.22,1.06)$ & 0.071 & $0.59(0.28,1.23)$ & 0.158 \\
\hline $1-2$ & $1.63(0.34,7 \cdot 80)$ & 0.542 & $0.65(0.32,1.33)$ & 0.239 & $0.75(0.38,1.5)$ & 0.421 \\
\hline$>2$ & 1 & & 1 & & 1 & \\
\hline \multicolumn{7}{|l|}{ Family size } \\
\hline$\geq 7$ & $0.11(0.03,0.45)$ & 0.002 & $0.38(0.19,0.77)$ & 0.007 & $0.60(0.32,1.14)$ & 0.117 \\
\hline $4-6$ & $0.34(0.13,0.89)$ & 0.029 & $0.59(0.34,1.03)$ & 0.064 & $0.57(0.34,0.95)$ & 0.031 \\
\hline$\leq 3$ & 1 & & 1 & & 1 & \\
\hline \multicolumn{7}{|c|}{ Households estimated annual income in ETB } \\
\hline$\leq 5000$ & $0.27(0.07,1.08)$ & 0.064 & $0.19(0.08,0.42)$ & 0.000 & $0.38(0.18,0.82)$ & 0.013 \\
\hline $5001-15000$ & $0.66(0.18,2.38)$ & 0.524 & $0.50(0.23,1.11)$ & 0.088 & $0.92(0.43,1.97)$ & 0.829 \\
\hline $15001-30000$ & $0.86(0.20,3.77)$ & 0.845 & $0.83(0.35,1.96)$ & 0.672 & $0.99(0.43,2.29)$ & 0.997 \\
\hline$\geq 30001$ & 1 & & 1 & & 1 & \\
\hline \multicolumn{7}{|l|}{ Respondents' religion } \\
\hline Orthodox/catholic & $0.77(0.07,9.03)$ & 0.835 & $1.28(0.50,3.25)$ & 0.606 & $2.37(0.99,5.68)$ & 0.053 \\
\hline Muslim & $3.19(0.86,11.79)$ & 0.835 & $0.53(0.24,1.16)$ & 0.113 & $2.87(1.44,5.71)$ & 0.003 \\
\hline Protestant & 1 & & 1 & & 1 & \\
\hline
\end{tabular}

AOR, adjusted odds ratio; ha, hectare; ETB, Ethiopian Birr.

Maximum Variance inflation factor: poultry $=2 \cdot 08$, meat $=2.08$ and eggs $=2 \cdot 08$; pseudo $R^{2}$ : poultry $=0.32$, meat $=0.28$ and eggs $=0.34$.

or seven or more (AOR $0 \cdot 11, P$ 0.002) members were more likely to have a low frequency of poultry consumption than households with three or fewer members. Family size of seven or more predicted reduced household probability of meat consumption by $62 \%$ (AOR $0 \cdot 38, P$ 0.007). An estimated annual income of 5000 ETB or less also reduced meat consumption probability of households by $81 \%$ (AOR $0.19, \quad P<0.001)$ compared to those earning more than 30000 ETB annually (Table 3).

Households with an estimated annual income of 5000 ETB or less (AOR 0.38, P 0.013), four to six family sizes (AOR $0.57, P 0.031$ ) and no chicken ownership (AOR 0.33, $P<$
0.001) were less likely to consume eggs. Households that did not own donkey were less likely to consume poultry (AOR $0 \cdot 25, P$ 0.017), meat (AOR 0.38, P 0.008) and eggs (AOR $0 \cdot 55, P 0 \cdot 06$ ) than their counterparts (Table 3).

Table 4 shows that households with more than 2 ha of agricultural land were more likely to report consuming milk on a daily basis than households with 1 ha or less (AOR $0.48, P$ $0 \cdot 039$ ). Households who owned cows were more likely to consume milk (AOR $0.42, P<0.001$ ) and milk products (AOR $0.35, P<0.001)$ frequently than households that did not own cows. Households with no cash crop production were more likely (AOR 3.01, P 0.003) to consume milk products 
Table 4. Ordinal logistic regression analysis on predictors of milk and milk products consumption frequencies by households in Hawassa Milkshed, Ethiopia $(N$ 422)

\begin{tabular}{|c|c|c|c|c|}
\hline \multirow[b]{2}{*}{ Characteristics } & \multicolumn{2}{|c|}{ Milk } & \multicolumn{2}{|c|}{ Milk products (yogurt, cheese, whey, etc.) } \\
\hline & AOR $(95 \% \mathrm{Cl})$ & $P$ & AOR $(95 \% \mathrm{Cl})$ & $P$ \\
\hline \multicolumn{5}{|c|}{ Household food insecurity } \\
\hline Insecure & $0.66(0.45,0.98)$ & 0.035 & $0.52(0.33,0.83)$ & 0.005 \\
\hline Secure & 1 & & 1 & \\
\hline \multicolumn{5}{|c|}{ Cash crops production: coffee, khat, etc. } \\
\hline No & $0.93(0.49,1.74)$ & 0.813 & $3.01(1.46,6.20)$ & 0.003 \\
\hline Yes & 1 & & 1 & \\
\hline \multicolumn{5}{|l|}{ Chicken ownership } \\
\hline No & $0.75(0.51,1.11)$ & 0.149 & $1 \cdot 10(0.69,1.76)$ & 0.684 \\
\hline Yes & 1 & & 1 & \\
\hline \multicolumn{5}{|l|}{ Donkey ownership } \\
\hline No & $0.91(0.49,1.70)$ & 0.768 & $1.01(0.53,1.93)$ & 0.979 \\
\hline Yes & 1 & & 1 & \\
\hline \multicolumn{5}{|l|}{ Sheep ownership } \\
\hline No & $0.63(0.33,1.21)$ & 0.169 & $0.44(0.22,0.90)$ & 0.024 \\
\hline Yes & 1 & & 1 & \\
\hline \multicolumn{5}{|l|}{ Goat ownership } \\
\hline No & $1.5(0.83,2.72)$ & $0 \cdot 182$ & $0.90(0.47,1.71)$ & 0.742 \\
\hline Yes & 1 & & 1 & \\
\hline \multicolumn{5}{|l|}{ Cow ownership } \\
\hline No & $0.42(0.28,0.64)$ & 0.000 & $0.35(0.21,0.58)$ & 0.000 \\
\hline Yes & 1 & & 1 & \\
\hline \multicolumn{5}{|l|}{ Ox ownership } \\
\hline No & $0.8(0.49,1.31)$ & 0.372 & $0.95(0.55,1.64)$ & 0.856 \\
\hline Yes & 1 & & 1 & \\
\hline \multicolumn{5}{|c|}{ Women's educational status } \\
\hline No education & $0.29(0.08,1.01)$ & 0.052 & $0.61(0.16,2 \cdot 36)$ & 0.471 \\
\hline Grades $1-5$ & $0.37(0.11,1.24)$ & 0.107 & $1.20(0.33,4.31)$ & 0.784 \\
\hline Grades $6-10$ & $0.67(0.20,2.22)$ & 0.517 & $0.87(0.24,3.09)$ & 0.827 \\
\hline Higher education & 1 & & 1 & \\
\hline \multicolumn{5}{|c|}{ Agriculture land ownership and size (ha) } \\
\hline No land & $0.71(0.22,2.26)$ & 0.557 & $0.55(0.12,2.49)$ & 0.441 \\
\hline$<1$ & $0.48(0.23,0.96)$ & 0.039 & $1.35(0.55,3.33)$ & 0.519 \\
\hline $1-2$ & $0.71(0.37,1.38)$ & 0.309 & $1.52(0.66,3.53)$ & 0.33 \\
\hline$>2$ & 1 & & 1 & \\
\hline \multicolumn{5}{|l|}{ Family size } \\
\hline$\geq 7$ & $0.73(0.41,1.32)$ & 0.3 & $0.99(0.49,2.02)$ & 0.995 \\
\hline $4-6$ & $0.72(0.44,1.18)$ & 0.19 & $0.86(0.47,1.55)$ & 0.608 \\
\hline$\leq 3$ & 1 & & 1 & \\
\hline \multicolumn{5}{|c|}{ Household estimated annual income in ETB } \\
\hline$\leq 5000$ & $0.48(0.23,1.02)$ & 0.055 & $0.37(0.16,0.84)$ & 0.017 \\
\hline $5001-15000$ & $0.61(0.29,1.30)$ & 0.204 & $0.47(0.21,1.05)$ & 0.066 \\
\hline $15001-30000$ & $1.51(0.66,3.47)$ & 0.331 & $0.43(0.17,1.08)$ & 0.074 \\
\hline$\geq 30001$ & 1 & & 1 & \\
\hline \multicolumn{5}{|l|}{ Respondents' religion } \\
\hline Orthodox/catholic & $1.84(0.80,4.24)$ & 0.15 & $1.96(0.71,5.43)$ & 0.196 \\
\hline Muslim & $1.94(1.03,3.64)$ & 0.04 & $2.74(1.35,5.56)$ & 0.005 \\
\hline Protestant & 1 & & 1 & \\
\hline
\end{tabular}

AOR, adjusted odds ratio; ha, hectare; ETB, Ethiopian Birr.

Maximum variance inflation factor: milk $=2.08$ and milk products $=2.08$; pseudo $R^{2}$ : milk $=0.27$ and milk products $=0.33$.

more frequently than households producing cash crops. In contrast to households with an estimated annual income of more than 30000 ETB, those with an annual income of less than 5000 ETB were less likely (AOR 0.37, P 0.017) to consume milk products.

\section{Discussion}

The purpose of the present study was twofold: (1) to assess household-level dietary behaviours related to the consumption of animal products and (2) to identify facilitators, constraints to and determinants of household-level ASF consumption. We found that poultry was not consumed by $92 \%$ of the the households, and meat was not consumed by $60 \%$ of the households over a one-month period. This is in agreement with other papers ${ }^{(40,41)}$ those described limited inclusion of ASF in diets of families in low- and middle-income countries (India, China and Latin America). However, there are studies in which better ASF consumption patterns were reported. In south Ethiopia, once per month consumption of meat was reported for 80,72 and $26.8 \%$ of households in Wolaita Sodo town ${ }^{(42)}$, Mirab Abaya ${ }^{(43)}$ and Hawassa city ${ }^{(44)}$. As the 
studies were conducted in towns, the difference in consumption practice from the present study could be subject to the availability of retailer butcher houses and households' interest to pay and purchasing power. The habit of frequent meat consumption in the immediate local culture may also have contributed. A study from Sudan ${ }^{(45)}$ also reported once per week meat consumption frequency for more than two-thirds (68 $\%)$ of the studied households. Overall, in the present study, meat consumption was constrained by the reported unavailability $(70 \%)$ and unaffordability $(80 \%)$ of the food product.

About a quarter of the studied households consumed milk once per day $(21 \%)$ or one to two times per week $(26 \%)$. According to a study conducted in East Shoa Zone in Ethiopia, $67-100 \%$ of households from urban areas and $67-87 \%$ of households from peri-urban areas consumed milk three to six times per week ${ }^{(46)}$. The variations could be due to study setting, socio-economic and food habit differences in urban and rural scenarios. A study conducted in China identified that urban dwellers consume more animal products than those in rural areas ${ }^{(47)}$. Animal product consumption also increased in response to income growth.

Eggs were consumed one to two times per week $(20 \%)$ or one to two times per month (19\%) by about one-fifths of the households during the 1-month period prior to the day of assessment. In the present study, egg consumption was found to be better than poultry, meat and fish. This could be because of relative availability $(78 \%)$ and affordability $(60 \%)$ of eggs, as many of the participants reported. However, egg consumption frequency in the present study was lower than a report from Hyderabad district in India, where daily egg consumption was reported for half $(51 \%)$ of the households ${ }^{(48)}$. Egg consumption habit, higher price as compared to plant-based food items and poultry production primarily for income generation ${ }^{(49,50)}$ might have constrained the consumption of eggs.

Meat was unavailable in the rural settings to more than two-thirds of research participants $(70 \%)$, where they usually shop, while $80 \%$ could not afford the price. Plant-based food products were more affordable than meat for $92 \%$ of the respondents. The present findings are supported by reports ${ }^{(49,51)}$ that identified poverty and high price of nutritious foods including animal products as constraints to ASF consumption. A study from Ghana ${ }^{(52)}$ identified low income and lack of market access as contributing factors for low ASF consumption.

Availability, positive attitudes to its quality, relative affordability, less effort needed to prepare and cook, storage and favourable beliefs about health benefits were found to be facilitators to the consumption of eggs. However, income generation priority from poultry rearing and higher price of egg $(93 \%)$ as a compared to plant-based food were the constraints identified. A large proportion of households $(91 \%)$ in Ethiopia rear chickens for the sake of income generation and savings ${ }^{(49,50)}$ rather than household-level consumption similar to the present findings.

Unlike the findings from the Amhara ${ }^{(53)}$ and Tigray ${ }^{(49)}$ regions of Ethiopia with more Orthodox Christians and from a review on meat consumption ${ }^{(54)}$, religion and related fasting did not hinder the use of ASF in the present study. This could be because of the dominating Protestant $(67 \%)$ and Muslim (28\%) religion followers in the present study areas, who do not abstain from the consumption of ASF during their fasting seasons.

Household food insecurity and ASF consumption pattern were associated. Food-insecure households were less likely to consume poultry, meat, eggs, milk and milk products than food-secure households. In Ethiopia, a 40-70 \% price increment was documented for nutritious food commodities like eggs, meat, dairy and other products since the year of $2005^{(55)}$. Studies from Jimma in Ethiopia ${ }^{(56)}$ and Sierra Tarahumara in Mexico ${ }^{(57)}$ identified households' shifting to inexpensive food items as a coping strategy for food insecurity. This could explain the inverse association between household food insecurity and ASF consumption frequencies observed in the present study districts.

The consumption of ASF is expected to increase when a household owns domestic animals as a source of food commodities and income for diversified diets. According to the results of the present study, households owning cows were likely to consume milk and milk products more frequently than households not owning cows. Households with chickens were also more likely to consume eggs than households with no chickens. Households with donkeys were more likely to consume poultry, meat and eggs than households without donkeys. Studies ${ }^{(58-61)}$ from Ethiopia have identified that donkeys contribute to human livelihood and household food security through their role in income generation and gender empowerment. This might have contributed to the observed positive association between donkey ownership and ASF consumption frequencies.

Lesser farmland size and cash crop production practice were inversely associated with households' dairy product consumption frequency. Land size is an important asset for farming households in the study districts. Larger land allows households to rear cows on free grazing ${ }^{(62)}$ to serve as a source of dairy products ${ }^{(63)}$. On the other hand, cash crops may constantly take over the limited landholding and make it unfit for traditional livestock farming that would contribute to ASF availability and access.

Education is an important tool for empowering human beings to positively influence livelihood ${ }^{(64,65)}$. In the present study, households with women with better education achievements were more likely to consume eggs than households with women who never attended formal education.

Larger family size has been discussed for its negative effect on household food security ${ }^{(6,67)}$ and that may be because it constrains households' food purchasing power and challenges intrahousehold food distribution. Correspondingly, in the present study, more family size was negatively associated with household-level poultry, meat and egg consumption. This may call for food-based interventions on the improvement of diversified agricultural production, family planning and income generation with nutrition education for the public at large.

Less eggs, meat and milk product consumption frequencies were associated with an estimated annual income of $5000 \mathrm{ETB}$ or less. In line with the observed negative association between low income and ASF consumption in the present study, a global 
analysis on the affordability of dietary recommendations ${ }^{(68)}$ mentioned that diets in low- and middle-income countries might face limitations for nutritious foods like eggs, meat, fish, dairy, fruits and vegetables, as they are high-cost food groups.

Despite comprehensively addressing evidence gaps related to ASF consumption patterns, because the present study is crosssectional, it cannot identify causal relationships between the identified predictors and respective ASF consumption ${ }^{(69,70)}$. Interpretation of the results must also consider the unavoidable methodologic limitations ${ }^{(71)}$ of consumption frequency assessment like an increased probability of recall bias, as the period for which respondents had to remember was a full month. It is also good to consider the possibility of respondents' desire to show being needy regardless of status.

\section{Conclusions}

Meat, poultry and fish were consumed less frequently than dairy and eggs. The consumption of poultry, meat and fish was nutritionally negligible. In general, ASF were not consumed often by households in the studied rural districts of Ethiopia. Unavailability, unaffordability, limited ASF consumption tradition, income generation priority from livestock rearing and higher price of ASF than plant-based foods were constraints identified.

Poverty as determined by food insecurity, income and property ownership hampered ASF consumption frequencies. Cow, chicken and donkey ownership amplified selected ASF consumption frequencies. Poultry, meat and eggs were less frequently consumed by households with the lowest estimated annual income category. Women's lack of formal schooling and larger family size also contributed to the less frequent consumption of some types of ASF. Policies and programmes on food-based nutrition interventions should focus on the improvement of diversified agricultural production through nutrition-sensitive agricultural extension, family planning, livelihood improvement, women's empowerment and job opportunities to generate income integrated with nutrition education and evaluate their effects on the nutritional status of the public at general and on ASF consumption patterns in particular.

\section{Supplementary material}

The supplementary material for this article can be found at https://doi.org/10.1017/jns.2021.52.

\section{Acknowledgments}

The authors acknowledge the School of Nutrition, Food Science and Technology-Hawassa University, Livestock System Intensification Lab-Project and administrative bodies of the study districts for the assistance they provided throughout the study process. We also forward our thanks to Professor Stoecker J. Babara, Professor Daniel J. Hoffman and Professor Martha Archuleta for the academic help they provided by editing the present paper for language.

This work was funded by the United States Agency for International Development (USAID) Bureau for Food Security under Agreement No. AID-OAA-L-15-00003 as part of Feed the Future Innovation Lab for Livestock Systems. Any opinions, findings, conclusions or recommendations expressed here are those of the authors alone. United States Agency for International Development (USAID) Bureau for Food Security had no role in the design, analysis or writing of the present article.

A.K.D., M.M., K.A. and D.H. conceptualised and designed the study; AKD involved in the supervision of data collection, data analysis, interpretation of results and manuscript drafting. A.K.D., M.M., K.A. and D.H. reviewed the manuscript. All authors read and approved the final manuscript.

There are no conflicts of interest.

\section{References}

1. Ritchie H \& Roser M (2019) Age structure. https://ourworldindata. org/age-structure (accessed March 2020).

2. UNICEF/WHO/World Bank (2017) Levels and Trends in Child Malnutrition.

3. UNICEF/WHO/World Bank (2019) Levels and Trends in Child Malnutrition.

4. World Health Organization (2020) Children: reducing mortality. https://www.who.int/news-room/fact-sheets/detail/children-reducingmortality\#_ftnref1 (accessed October 2020).

5. Huybregts L \& Lachat C (2019) Drivers of under-five stunting trend in 14 low- and middle-income countries since the turn of the demographic and health surveys. Nutrients 11, 1-12.

6. Headey D, Hirvonen K \& Hoddinott J (2018) Animal sourced foods and child stunting. Am J Agric Econ 100, 1302-1319.

7. Krasevec J, An X, Kumapley R, et al. (2017) Diet quality and risk of stunting among infants and young children in low- and middle-income countries. Matern Child Nutr 13, 1-11.

8. Kaimila Y, Divala O, Agapova SE, et al. (2019) Consumption of animalsource protein is associated with improved height-for-age $\mathrm{Z}$ scores in rural Malawian children aged 12-36 months. Nutrients 11, 1-21.

9. Schönfeldt HC, Pretorius B \& Hall N (2013) The impact of animal source food products on human nutrition and health. South African J Anim Sci 43, 394-412.

10. Hoffman JR \& Falvo MJ (2004) Protein - which is best? J Sport Sci Med 3, 118-130.

11. Neumann C, Harris DM \& Rogers LM (2002) Contribution of animal source foods in improving diet quality and function in children in the developing world. Nutr Res 22, 193-220.

12. Schmid A \& Walther B (2013) Natural vitamin D content in animal products. Adv Nutr 4, 453-462.

13. Murphy SP \& Allen LH (2003) Nutritional importance of animal source foods. J Nutr 133, 3965-3971.

14. Neumann CG, Murphy SP, Gewa C, et al. (2007) Meat supplementation improves growth, cognitive, and behavioral outcomes in Kenyan children. J Nutr 137, 1119-1123.

15. Eaton JC, Rothpletz-Puglia P, Dreker MR, et al. (2019) Effectiveness of provision of animal-source foods for supporting optimal growth and development in children 6 to 59 months of age. Cocbrane Database Syst Rev 2, CD012818.

16. Darapheak C, Takano T, Kizuki M, et al. (2013) Consumption of animal source foods and dietary diversity reduce stunting in children in Cambodia. Int Arch Med 6, 1.

17. Iannotti LL, Lutter CK, Stewart CP, et al. (2017) Eggs in early complementary feeding and child growth: a randomized controlled trial. Pediatrics 140, 1.

18. Adesogan AT, Havelaar AH, McKune SL, et al. (2020) Animal source foods: sustainability problem or malnutrition and sustainability solution? Perspective matters. Glob Food Sec 25, 1-7.

19. Central Statistical Agency (CSA) of Ethiopia and ICF (2016) Demographic and Health Survey Key Indicators. Addis Ababa, Ethiopia: CSA and ICF. 
20. Federal Democratic Repulic of Ethiopia (2019) The Seqota Declaration committed to ending stunting in children under two by 2030. https://www.bigwin.org/nm_pent_bigwp/wp-content/uploads/ 2019/10/Extended Note.pdf (accessed March 2020).

21. Gebregziabher G (2019) Healtby sustainable diets for all: a view from Ethiopia. https://news.trust.org/item/20190207154412-p07kz/ (accessed September 2020)

22. Workicho A, Belachew T, Feyissa GT, et al. (2016) Household dietary diversity and animal source food consumption in Ethiopia: evidence from the 2011 welfare monitoring survey. BMC Public Health 16, 1-11.

23. Ethiopian Public Health Institute (2013) Etbiopia National Food Consumption Survey. Addis Ababa, Ethiopia: Ethiopian Public Health Institute (EPHI).

24. Aemro M, Mesele M, Birhanu Z, et al. (2013) Dietary diversity and meal frequency practices among infant and young children aged 6-23 months in Ethiopia: a secondary analysis of Ethiopian Demographic and Health Survey 2011. J Nutr Metab 2013, 1-8.

25. Beyene M, Worku AG \& Wassie MM (2015) Dietary diversity, meal frequency and associated factors among infant and young children in Northwest Ethiopia: a cross-sectional study. BMC Public Health 15, 1.

26. Dangura D \& Gebremedhin S (2017) Dietary diversity and associated factors among children 6-23 months of age in Gorche district, Southern Ethiopia: cross-sectional study. BMC Pediatr 17, 1-7.

27. Forsido SF, Kiyak N, Belachew T, et al. (2019) Complementary feeding practices, dietary diversity, and nutrient composition of complementary foods of children 6-24 months old in Jimma Zone, Southwest Ethiopia. J Health Popul Nutr 38, 14.

28. Working Group on Infant and Young Child Feeding Indicators (2007) Developing and Validating Simple Indicators of Dietary Quality of Infants and Young Children in Developing Countries: Additional Analysis of 10 Data Sets. Report submitted to the Food and Nutrition Technical Assistance Project. FHI 360.

29. Gatahun EA (2015) Dietary diversity feeding practice and determinants among children aged 6-23 months in Kemba Woreda, Southern Ethiopia implication for public health intervention. J Nutr Food Sci. S13. doi: 10.4172/2155-9600.S13-003.

30. Solomon D, Aderaw Z \& Tegegne TK (2017) Minimum dietary diversity and associated factors among children aged 6-23 months in Addis Ababa, Ethiopia. Int J Equity Health 16, 1-9.

31. Central Statistical Agency (CSA) of Ethiopia and ICF (2016) Demographic and Health Survey. Addis Ababa, Ethiopia: CSA and ICF.

32. Amare B, Moges B, Moges F, et al. (2012) Nutritional status and dietary intake of urban residents in Gondar, Northwest Ethiopia. BMC Public Health 12, 1.

33. Hall AG, Ngu T, Nga HT, et al. (2017) An animal-source food supplement increases micronutrient intakes and iron status among reproductive-age women in rural Vietnam. J Nutr 147, 1200-1207.

34. Weldehaweria NB, Misgina KH, Weldu MG, et al. (2016) Dietary diversity and related factors among lactating women visiting public health facilities in Aksum town, Tigray, Northern Ethiopia. BMC Nutr 2, 1-9.

35. Federal Democratic Republic of Ethiopia (2018) Food and Nutrition Policy. Food and Nutrition Bulletin. https://www.nipn.ephi.gov.et/sites/ default/files/2020-05/Food\%20and\%20Nutrition\%20Policy.pdf

36. Government of Ethiopia (2016) National Nutrition Program 20162020. Addis Ababa, Ethiopia: Federal Democratic Republic of Ethiopia.

37. Brandsma W, Mengistu D, Kassa B, et al. (2012) The Major Ethiopian Milksheds; Wageningen. Wageningen UR (University \& Research Centre) Livestock Research. Livestock Research Report 735, 245 blz. Wageningen University, pp. 1-245.

38. Lemeshow S, Jr DWH, Klar J, et al. (1991) Adequacy of sample size in health studies. Biometrics 47, 347.

39. Food and Nutrition Technical Assistance Project (FANTA) (2007) Household food insecurity access scale (HFIAS) for measurement of food access: indicator guide. I Chem Inf Model 53, 1689-1699.

40. Abegaz, GA., Hassen, IW. \& Minten, B. (2018) Consumption of Animal-Source Foods in Ethiopia: Patterns, Changes, and Determinants.
ESSP Working Papers 113, International Food Policy Research Institute (IFPRI).

41. Delgado C, Rosegrant M, Steinfeld H, et al. (1999) Livestock to 2020 the Next Food Revolution. Report No.: 28.

42. Amistu K, Ermias B \& Asrat A (2017) Consumer preference of raw beef ('Kurt') in Wolaita Sodo Town, Southern Ethiopia. J Food Dairy Technol 5, 7-13.

43. Yibrah T \& Esheti A (2017) Assessment of meat consumption pattern in Mirab Abaya Woreda, Southern Ethiopia. Arch Vet Sci Technol 2017, 1-6.

44. Lijalem T, Beyan M \& Banerjee S (2013) Meat consumption patterns in Hawassa City, Southern Ethiopia. Am Sci Res J Eng Technol Sci 3, 2313-4410.

45. Khalid FA, Ali AKM, Ali SA, et al. (2017) Households' dietary habits and food consumption patterns in Hamishkoreib locality, Kassala State. Sudan J Ethn Foods 4, 181-186.

46. Melesse K \& Beyene F (2009) Consumption pattern of milk and milk products in Ada'a woreda, East Shoa Zone, central Ethiopia. Livest Res Rural Dev 21, 4.

47. Streeter JL (2017) Socioeconomic factors affecting food consumption and nutrition in China: empirical evidence during the 19892009 period. Chinese Econ 50, 168-192.

48. Memon A, Memon AS, Soomro AH, et al. (2009) Study on consumption of chicken eggs in Hyderabad District. Pak J Nutr 8, 1480-1485.

49. Haileselassie M, Redae G, Berhe G, et al. (2020) Why are animal source foods rarely consumed by 6-23 months old children in rural communities of Northern Ethiopia? A qualitative study. PLoS One 15, e0230527.

50. Hundie D, Goshu G, Tamir B, et al. (2019) Assessment on rural poultry production and marketing system of Horro chicken ecotypes in Western Ethiopia. J Agric Ext Rural Dev 11, 248-259.

51. Pachón H, Simondon KB, Fall ST, et al. (2007) Constraints on the delivery of animal-source foods to infants and young children: case studies from five countries. Food Nutr Bull 28, 215-220.

52. Colecraft E, Marquis GS, Aryeetey R, et al. (2006) Constraints on the use of animal source foods for young children in Ghana: a participatory rapid appraisal approach. Ecol Food Nutr 45, 351-377.

53. Kim SS, Nguyen PH, Tran LM, et al. (2019) Maternal behavioural determinants and livestock ownership are associated with animal source food consumption among young children during fasting in rural Ethiopia. Matern Child Nutr 15, 1-9.

54. Seleshe S, Jo C \& Lee M (2014) Meat consumption culture in Ethiopia. Korean J Food Sci Anim Resour 34, 7-13.

55. Minten B \& Fantu B (2020) Improving the evidence and policies for better performing livestock systems in Ethiopia. https://livestocklab. ifas.ufl.edu/media/livestocklabifasufledu/pdf-/results-summary/ BRIEF-Minten_IFPRI_Evidence-and-Policy-for-better-livestocksystems-_Ethiopia_final-2020_04_11.pdf

56. Asesefa Kisi M, Tamiru D, Teshome MS, et al. (2018) Household food insecurity and coping strategies among pensioners in Jimma Town, South West Ethiopia. BMC Public Health 18, 1-8.

57. Cordero-Ahiman OV, Santellano-Estrada E \& Garrido A (2018) Food access and coping strategies adopted by households to fight hunger among indigenous communities of Sierra Tarahumara in Mexico. Sustain 10, 1-14.

58. Geiger M, Hockenhull J, Buller H, et al. (2020) Understanding the attitudes of communities to the social, economic, and cultural importance of working donkeys in rural, peri-urban, and urban areas of Ethiopia. Front $\operatorname{Vet} S_{c i}$ 7, 1-13.

59. Marshall K \& Ali Z (2000) Gender issues in donkey use in rural Ethiopia. Nerthel, 224.

60. Valette D (2015) Invisible workers. The economic contributions of working donkeys, horses and mules to livelihoods. https:// www. thebrooke.org/sites/default/files/Advocacy-and-policy/Invisibleworkers-report.pdf

61. Angara TEE, Ismail AA \& Ibrahim AM (2011) The role of donkeys in income generation and the impact of endoparasites on their performance. J Veternary Med Anim Prod 2, 65-89. 
62. Duressa D, Kenea D, Keba W, et al. (2014) Assessment of Livestock Production System and Feed Resources Availability in Three Villages of Diga District Ethiopia. Nairobi, Kenya: International Livestock research Institute.

63. Rahman SMR, Hashan S, Shahjahan MD, et al. (2001) Ownership of livestock and land size. J Biol Sci 1, 960-962.

64. Tran TA, Tran TQ, Tran NT, et al. (2020) Nguyen HT. The role of education in the livelihood of households in the Northwest region. Vietnam Educ Res Policy Pract 19, 63-88.

65. Miller LC, Joshi N, Lohani M, et al. (2017) Women's education level amplifies the effects of a livelihoods-based intervention on household wealth, child diet, and child growth in rural Nepal. Int J Equity Health 16, 1-17.

66. Harris-Fry H, Shrestha N, Costello A, et al. (2017) Determinants of intra-household food allocation between adults in South Asia: a systematic review. Int J Equity Health 16, 1-21.
67. Agidew AA \& Singh KN (2018) Determinants of food insecurity in the rural farm households in South Wollo Zone of Ethiopia: the case of the Teleyayen sub-watershed. Agric Food Econ 6, 1.

68. Hirvonen K, Bai Y, Headey D, et al. (2020) Affordability of the EAT-Lancet reference diet: a global analysis. The Lancet Global Health 8, e59-e66.

69. Jorn O, Kaare C, Jeff M, et al. (2010) Design options. In An Introduction to Epidemiology for Health Professinals, 2nd ed. [A Wolfgang and P Iris, editors], pp. 51-57. New York: Springer Science + Business Media, LLC.

70. Mark W (1999) Assessing risk factors. In Epidemiology: Study Design and Data Analysis. [C Chris and VZ Jim, editors], pp. 107-141. New York/Washington, D.C.: Chapman \& Hall/CRC.

71. Gibson RS (2005) Principles of Nutritional Assessment. 2nd ed. New York: Oxford University Press. 